\title{
EFEITO DE DIFERENTES NÍVEIS DE PROTEÍNA BRUTA EM RAÇÕES PARA CRESCIMENTO DE CARPAS (Cyprinus carpio L., 1758) EM DUAS DENSIDADES
}

\author{
ALVARO GRAEFF ${ }^{1}$ \\ EVALDO NAZARENO PRUNER ${ }^{2}$
}

\begin{abstract}
RESUMO - O efeito de rações com diferentes níveis de proteína bruta sobre o peso, comprimento, conversão alimentar e sobrevivência das carpas foi avaliado no período de 120 dias (19 de novembro a 20 de março de 1996 a 1998. Os peixes foram povoados com peso médio conjunto de $1,38 \mathrm{~g}$ e comprimento médio conjunto de 4,15 cm com 60 dias de idade. O delineamento experimental foi o inteiramente casualizado, em um esquema de tratamentos fatorial de $4 \times 2$, em que testaram-se 4 doses de proteína bruta em 2 densidades de estocagem $\left(15\right.$ e 30 peixes $/ \mathrm{m}^{2}$ ), com 4 repetições por tratamento. Os peixes receberam a ração diariamente, na quantidade de $5 \%$ do peso vivo, sendo reajustados a cada 30 dias, quando todos os peixes foram medidos e pesados. O comportamento de cada variável ao longo do tempo para cada tratamento foi estudado pela análise de regressão polinomial. Para a variável peso conjunto, os resultados, usando a densidade 15 , foram: 8,$88 ; 10,23$;
\end{abstract}

10,80 e $11,88 \mathrm{~g}$, e com a densidade $30,5,49 ; 6,83 ; 8,06$ e 9,19 g, respectivamente nos níveis de 20, 27, 34 e 41 $\%$ de proteína bruta, e a equação que melhor descreve o comportamento é $\mathrm{Y}=4.23+0.27 \mathrm{X}$. Para o comprimento conjunto, os resultados obtidos com a densidade 15 foram: 8,$03 ; 8,24 ; 8,54$ e $8,98 \mathrm{~cm}$, e com a densidade $30,6,76 ; 7,11 ; 7,57$ e $7,83 \mathrm{~cm}$, respectivamente nos níveis crescentes de proteína bruta, e a equação que melhor descreve o comportamento é Y $=2.80+0.08 \mathrm{X}$. A variável conversão alimentar conjunta não diferiu significativamente pelas densidades e a equação que melhor descreve o comportamento em função dos níveis de proteína bruta na ração é Y = 4,72 - 0.04 X. Concluindo, podese afirmar que o efeito das densidades não influenciou no crescimento, e que a melhor média de peso médio final foi observada no tratamento com densidade de 15 e 30 pei$\mathrm{xes} / \mathrm{m}^{2}$, com $41 \%$ de $\mathrm{PB}$, sendo mais adequada às necessidades da espécie nessa idade.

TERMOS PARA INDEXAÇÃO: Carpa comum, densidade, proteína bruta.

\section{EFFECT OF DIFFERENT LEVELS OF CRUDE PROTEIN IN RATIONS ON GROWTH OF CARPS (Cyprinus carpio L., 1758) IN TWO DENSITIES}

\begin{abstract}
The effects of rations with different levels of crude protein on weight, length, alimentary conversion and survival of carps were investigated on a 120-day period (November 19th to March 20th - from 1996 to 1998). The fish were stocked with average weight of $1.38 \mathrm{~g}$ and average length of $4.15 \mathrm{~cm}$. with 60 days of age. The experiments followed the experimental outline entirely randomized, in a factorial outline of treatments of $4 \times 2$ where four doses of crude protein were tested in two densities of storage (15 and 30 fish per square meter), with four repetitions per treatment. The fish received a daily ration rated in 5\% of live weight, which was readjusted every 30 days when all fish were measured and weighed. The
\end{abstract}

behavior of each variable throughout the time for each treatment was studied by polynomial regression analysis. For the overall weight variable, the results obtained using density 15 were: $8.88 ; 10.23 ; 10.80$ and $11.88 \mathrm{~g}$, and with density of 30 were: $5.49 ; 6.83 ; 8.06$ and $9.19 \mathrm{~g}$, respectively for the levels of $20,27,34$ and $41 \%$ of crude protein; the equation that best describes the behavior is $\mathrm{Y}=4.23+0.27 \mathrm{X}$. For the overall length variable, the results obtained using density 15 were: $8.03 ; 8.24 ; 8.54$ and $8.98 \mathrm{~cm}$, and with density $30: 6,76 ; 7.11 ; 7.57$ and $7.83 \mathrm{~cm}$, respectively in growing levels of crude protein and the equation that best describes this behavior is $\mathrm{Y}=2.80+0.08 \mathrm{X}$. The feed conversion variable didn't differ significantly for

1. Médico Veterinário - Nutrição/EPAGRI - Estação de Piscicultura de Caçador, SC. agraeff@epagri.rct-sc.br

2. Médico Veterinário - Reprodução/EPAGRI - Caixa Postal 591 - 89500-000 - Caçador, SC. 
the different densities. The equation that best describes the behavior regarding the levels of crude protein in the ration is $\mathrm{Y}=4.72-0.04 \mathrm{X}$. As a final conclusion it can be affirmed that the effect of densities hadn't influenced the fish growth and the best average of final medium weight was observed in treatment with densities of 15 and 30 fish per square meter with $41 \%$ of $\mathrm{PB}$, which suits more the needs of the species at this age.

INDEX TERMS: Common carp, densities, crude protein.

\section{INTRODUÇÃO}

A região do meio-oeste catarinense, por apresentar condições potenciais para o desenvolvimento da piscicultura, vem sendo alvo de grande interesse para essa atividade. Dentre as espécies exóticas que vem sendo utilizadas em cultivos, destaca-se a Carpa comum (Cyprinus carpio var. specularis), por apresentar quase todas características e atributos desejáveis para o sucesso de uma criação, pois além de suas características comerciais nas Regiões Sul e Sudeste do Brasil, possui marcada resistência às enfermidades e ao manuseio, elevada fecundidade e se adapta rapidamente às condições de cativeiro.

Pela aquicultura, parte dos métodos de manejo atuais precisam ser alterados, cabendo ao nutricionista a substituição de forma total ou parcial da alimentação natural (Pezzato et al., 1986). Para tanto, é necessário aumentar o conhecimento das necessidades nutricionais das espécies a ser cultivadas com fins econômicos. Embora, certos resultados possam ser controvertidos, estão de acordo com os fatores envolvidos na utilização da proteína na dieta. Os mais importantes incluem o padrão de aminoácidos da proteína, o nível de consumo, o conteúdo de energia da dieta e o estado fisiológico dos animais (Cowey, 1978).

Segundo Pereira Filho (1978), apesar de a piscicultura ser praticada desde antes da Era Cristã e a alimentação artificial de peixes tenha começado nos mosteiros da Europa na Idade Média, somente no século $\mathrm{XX}$ é que foram realizados os primeiros trabalhos científicos sobre nutrição. Durante os últimos 30 anos, houve um grande desenvolvimento nos conhecimentos científicos básicos sobre nutrição de peixes, possibilitando a elaboração de dietas artificiais para as várias espécies cultivadas em todo mundo (Nose, 1967).

$\mathrm{O}$ primeiro relato oficial de trabalhos com exigência em proteína foi com o salmão "Chinook" (Oncorhynchus tschawytscha) por De Long, Halver e Mertz (1958). Posteriormente, foi repetido por vários pesquisadores para muitas espécies de peixes. Ling (1973) já observava que o fornecimento de alimentação suplementar possibilitava rápido crescimento dos peixes em condições de elevada densidade de estocagem.
Tamassia e Kreuz (1988), em estudos de casos, concluíram que o aumento da produtividade da piscicultura está condicionada a diminuir os seus custos unitários mediante fornecimento regular de subprodutos agropecuários e aumento da biomassa estocada inicialmente.

Muitos dos problemas relacionados com a reprodução ou com controle de doenças de peixes também estão intimamente ligados ao aspecto nutricional do animal, aumentando ainda mais a importância dos estudos sobre as exigências nutricionais de cada espécie (Carneiro et al., 1990).

A densidade de estocagem na fase juvenil é importante para evitar o comportamento agonístico, ao mesmo tempo em que proporciona resistência aos predadores, e consequientemente aumento de produtividade (Knights, 1987). Nesse aspecto, o conhecimento de densidade de estocagem assume papel relevante, não só pelo máximo aproveitamento do espaço ocupado pelo peixe, contribuindo para o aumento da produtividade, como também pela determinação dos custos de produção em relação ao capital investido, evitando alterações fisiológicas, como a supressão do sistema imunológico, perda do equilíbrio osmótico e diminuição da alimentação, com conseqüiente redução do crescimento (Parker, 1984).

Assim pelos conhecimentos acumulados nesse importante campo de produção animal, pôde-se estabelecer os requisitos nutricionais de algumas espécies, os quais constam de publicações do National Research Council - NRC (1993).

Com o presente trabalho objetivou-se testar rações com níveis crescentes de proteína bruta e energia metabolizável em duas densidades de estocagem, porém, com os mesmos ingredientes, tendo-se em vista a determinação da composição de uma dieta aconselhável para a recria de alevinos.

\section{MATERIAL E MÉTODOS}

Os experimentos foram realizados na Estação de Piscicultura de Caçador/EPAGRI, em caixas de cimento amianto com capacidade para 1.000 litros de água, em número de 32 parcelas, abastecidos individualmente com água derivada do açude de abastecimento na vazão de 0,5 litro por minuto.

Ciênc. agrotec., Lavras. V.27, n.4, p.894-902, jul./ago., 2003 
O período experimental foi em três anos (1996 a 1998), nos meses de 19 novembro a 20 março, por um período de 120 dias, a partir de 7 dias de adaptação dos alevinos em cada parcela experimental, procurando em cada ano iniciar os experimentos com alevinos de idades e pesos semelhantes.

$\mathrm{O}$ delineamento experimental foi inteiramente ao acaso, em um fatorial de $4 \times 2$, em que testaram-se quatro dietas crescentes em proteína bruta $(20,27,34,41 \%$ de PB) em duas densidades (15 e 30 peixes/metro quadrado) com quatro repetições por tratamento. Fixou-se a energia metabolizável em 2.900 $\mathrm{kcal} \mathrm{EM} / \mathrm{kg}$ de ração. As dietas foram formuladas com os mesmos ingredientes, porém em diferentes proporções percentuais, de modo a apresentarem os teores de proteína bruta crescente e a energia estabilizada, conforme a Tabela 1. Foram estocados 21 e 42 peixes $(C y$ prinus carpio var. specularis) em cada parcela, respectivamente na densidade 15 e 30 peixes $/ \mathrm{m}^{2}$, com peso médio conjunto de 1,38 grama e comprimento médio conjunto de 4,15 centímetros com \pm 60 dias de idade nos três anos, sendo arraçoados na base de $5 \%$ do peso vivo ao dia.

As condições da água, que provêm de um tanque de abastecimento, foram coletadas e analisadas a cada quinze dias para as variáveis $\mathrm{pH}$, com peagômetro marca Corning (PS-30), transparência com disco de Secchi, oxigênio dissolvido, gás carbônico, dureza, alcalinidade e amônia total, por meio de um kit para análise de água (marca alfa-tecnoquímica) no Laboratório de Qualidade de Água/Epagri - Caçador. O período de observação iniciou-se na segunda quinzena da implantação dos experimentos e terminou quinze dias após o termino dos mesmos, por um período de três anos.

As observações de temperatura da água foram feitas diariamente $(9$ h) com termômetro eletrônico (Thies Clima) no momento em que os peixes recebiam a ração diária. Também verificaram-se a temperatura ambiente e umidade com um aparelho de corda (marca Wilh-Lambrech Gmbh Gottingen).

TABELA 1 - Composição da ração básica.

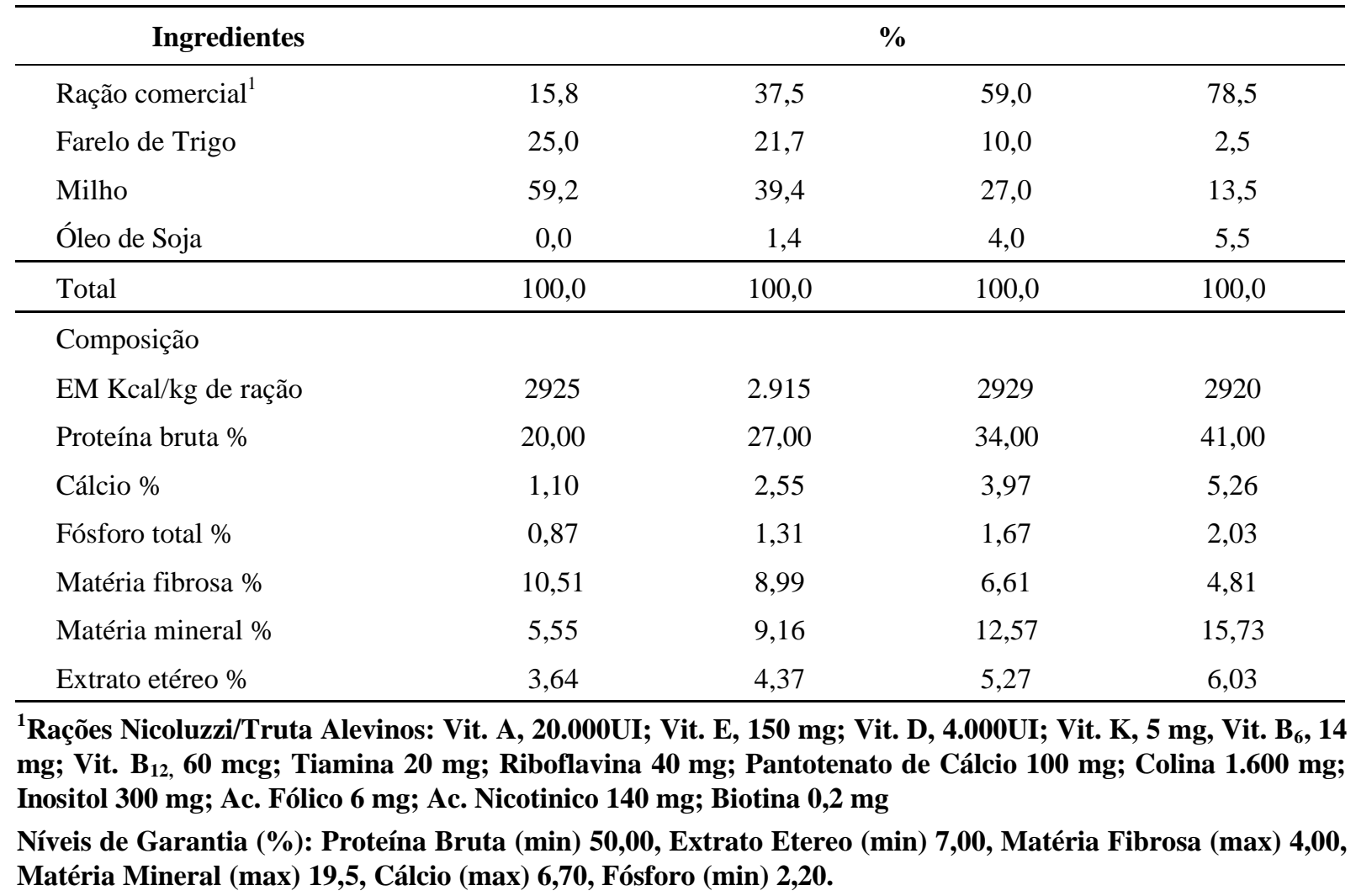

Ciênc. agrotec., Lavras. V.27, n.4, p.894-902, jul./ago., 2003 
A avaliação dos peixes foi feita a cada 30 dias utilizando-se $100 \%$ dos peixes estocados, quando foram tomadas as medidas de comprimento total por meio de um ictiômetro e o peso individual em uma balança eletrônica com precisão de $0,01 \mathrm{~g}$ (marca Marte). Sempre que essas atividades eram feitas, os peixes eram sedados com 3,0 ml de quinaldina para 15 litros de água. Após 120 dias de experimento de cada ano, os peixes foram despescados e feitas as avaliações quantitativas, compreendendo as evoluções de crescimento em peso e comprimento, sobrevivência e conversão alimentar.

\section{RESULTADOS E DISCUSSÃO}

A temperatura média mensal da água durante o período experimental (Figura 1) manteve-se entre 22,9 e $27,2^{\circ} \mathrm{C}$, ficando a média do período em $25,1^{\circ} \mathrm{C}$ nos três anos dos experimentos. Arrignon (1979), Makinouchi (1980) e Castagnolli (1986) afirmaram que "o melhor crescimento das carpas se dá entre $24^{\circ} \mathrm{C}$ a $28^{\circ} \mathrm{C}$ "; assim sendo, a variação da temperatura nos períodos experimentais não limitou o crescimento dos peixes (Tabela 2).

Também a temperatura média mensal do ambiente durante os três anos dos experimentos, ou seja, entre os meses de novembro a março manteve-se entre 17,8 e $23,8^{\circ} \mathrm{C}$, isto é, foi ligeiramente acima do normal para a região para essa época do ano, favorecendo, com isso o aumento da produtividade natural nas águas.
Todos os parâmetros de qualidade da água em 1996 e 1997 estavam normais para a criação dos peixes. Na avaliação da qualidade de água em 1998, os parâmetros; $\mathrm{pH}$, oxigênio e amônia estavam dentro do preconizado por Woynarowich (1985), Castagnolli (1992), Huet (1978) e Lukowicz (1982) para o desenvolvimento das carpas. Somente a transparência (Figura 2) aumentou nos últimos 60 dias, avaliação essa medida pelo disco de Secchi, e que não recomendável para a piscicultura orgânica, em função da redução da biomassa natural em suspensão, conforme Woynarowich (1985) afirmou em seu trabalho, mas sendo compensada pelo aumento da conversão alimentar (Tabela 3).

Também o nível de gás carbônico (Figura 2), em função da adubação orgânica, iniciou-se muito alto, ou seja, acima de $10 \mathrm{mg} / \mathrm{litro}$, o que é critico, mas foi normalizando-se com o desenvolvimento do experimento até estar novamente alto nos últimos 15 dias deste experimento, mas não comprometendo os resultados, conforme Arrignon (1979) preconiza. A dureza também (Figura 2) esteve abaixo do recomendável por Boyd (1997), que é entre 50 e $80 \mathrm{mg} /$ litro de $\mathrm{CaCO}_{3}$, ou seja, oscilou entre 20 a 50 $\mathrm{mg} /$ litro no inicio do experimento. E a alcalinidade (Figura 2), durante grande parte do experimento, esteve abaixo de $30 \mathrm{mg} / \mathrm{litro}$, o que indicaria necessidade de calagem (Boyd, 1997), mas apesar disso não trouxe oscilações no pH e nem alterações comportamentais nos peixes. Concluindo, os diferentes tipos de ração e densidade não interferiram significativamente nas características físicas e químicas da água dos experimentos.

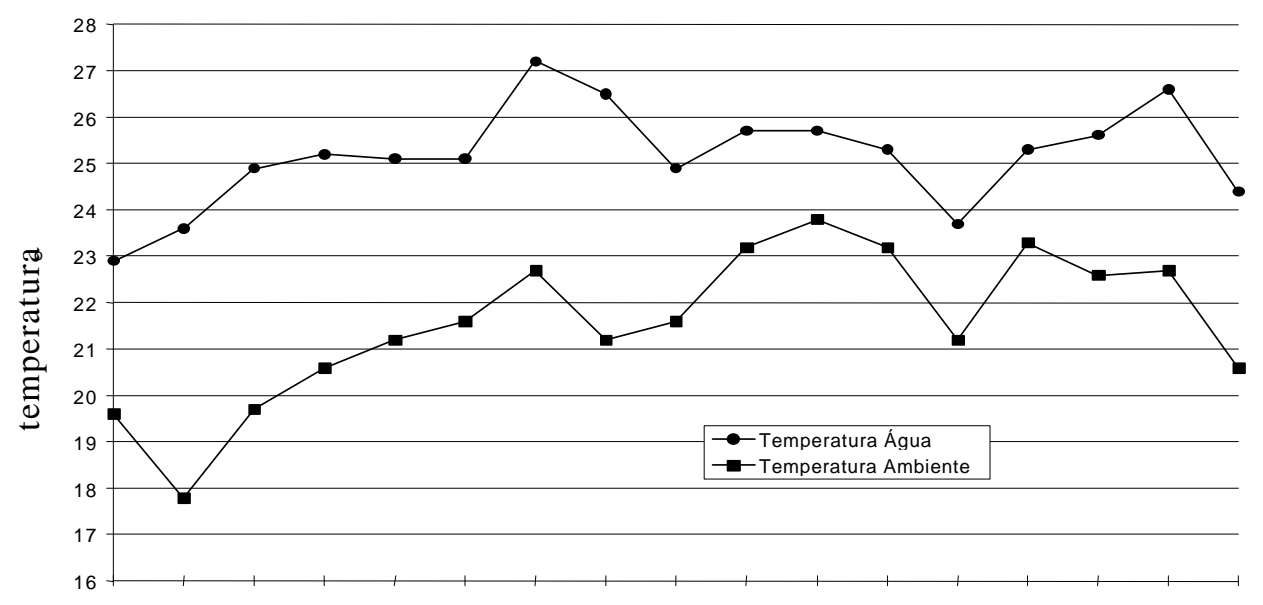

19/Nov 26/Nov 09/Dez 16/Dez 23/Dez30/Dez 07/Jan 14/Jan 21/Jan 27/Jan 04/Fev11/Fev 18/Fev25/Fev 04/Mar 11/Mar 18/Mar datas

FIGURA 1 - Temperatura $\left({ }^{0} \mathrm{C}\right)$ média da água e meio ambiente. 
TABELA 2 - Média geral nos três experimentos (1996 a 1998) do peso médio (g) e comprimento médio (cm) de alevinos de carpa comum (Cyprinus carpio var. specularis) em duas densidades e quatro níveis de proteína bruta.

\begin{tabular}{|c|c|c|c|c|c|c|c|c|c|c|c|c|c|c|c|c|}
\hline \multirow{3}{*}{$\begin{array}{c}\text { PB } \\
(\%)\end{array}$} & \multicolumn{8}{|c|}{ Peso médio (g) } & \multicolumn{8}{|c|}{ Comprimento médio (cm) } \\
\hline & \multicolumn{2}{|c|}{20} & \multicolumn{2}{|c|}{27} & \multicolumn{2}{|c|}{34} & \multicolumn{2}{|c|}{41} & \multicolumn{2}{|c|}{20} & \multicolumn{2}{|c|}{27} & \multicolumn{2}{|c|}{34} & \multicolumn{2}{|c|}{41} \\
\hline & 15 & 30 & 15 & 30 & 15 & 30 & 15 & 30 & 15 & 30 & 15 & 30 & 15 & 30 & 15 & 30 \\
\hline Inicio & 1,38 & 1,38 & 1,38 & 1,38 & 1,38 & 1,38 & 1,38 & 1,38 & 4,15 & 4,15 & 4,15 & 4,15 & 4,15 & 4,15 & 4,15 & 4,15 \\
\hline $1^{0}$ aval. & 2,40 & 1,90 & 2,30 & 1,90 & 2,40 & 2,00 & 2,40 & 2,00 & 5,00 & 4,70 & 5,00 & 4,80 & 5,20 & 4,90 & 5,20 & 4,80 \\
\hline $2^{\mathrm{a}}$ aval. & 4,40 & 2,80 & 4,70 & 3,00 & 4,50 & 3,60 & 4,70 & 3,50 & 6,30 & 5,40 & 6,20 & 5,50 & 6,20 & 5,80 & 6,40 & 5,80 \\
\hline $3^{\mathrm{a}}$ aval. & 6,60 & 3,80 & 6,50 & 4,40 & 7,70 & 5,60 & 8,30 & 5,70 & 7,30 & 6,00 & 7,30 & 6,20 & 7,30 & 6,70 & 7,40 & 6,80 \\
\hline Final & 8,88 & 5,49 & 10,23 & 6,83 & 10,8 & 8,06 & 11,88 & 9,20 & 8,03 & 6,76 & 8,24 & 7,11 & 8,54 & 7,57 & 8,98 & 7,83 \\
\hline
\end{tabular}

TABELA 3 - Média geral nos três experimentos (1996 a 1998) da taxa de sobrevivência, conversão alimentar de alevinos de carpa comum (Cyprinus carpio var. specularis) em duas densidades e quatro níveis de proteína bruta.

\begin{tabular}{|c|c|c|c|c|c|}
\hline \multirow{2}{*}{$\begin{array}{c}\text { Proteína Bruta } \\
(\%)\end{array}$} & \multirow{2}{*}{$\begin{array}{l}\text { Densidade } \\
\text { Peixe/m² }\end{array}$} & \multicolumn{2}{|c|}{ Número de Peixes } & \multirow{2}{*}{$\begin{array}{c}\text { Sobrevivência } \\
\text { (\%) }\end{array}$} & \multirow{2}{*}{ Conversão Alimentar } \\
\hline & & Início & Final & & \\
\hline \multirow{2}{*}{20} & 15 & 84 & 79 & 94,04 & 3,51 \\
\hline & 30 & 168 & 156 & 92,86 & 4,18 \\
\hline \multirow{2}{*}{27} & 15 & 84 & 75 & 89,28 & 2,82 \\
\hline & 30 & 168 & 157 & 93,45 & 3,71 \\
\hline \multirow{2}{*}{34} & 15 & 84 & 74 & 88,09 & 3,05 \\
\hline & 30 & 168 & 152 & 90,47 & 3,47 \\
\hline \multirow{2}{*}{41} & 15 & 84 & 74 & 88,09 & 2,91 \\
\hline & 30 & 168 & 156 & 92,85 & 2,89 \\
\hline
\end{tabular}

A sobrevivência obtida nos quatro tratamentos (Tabela 3) foi, em média, acima de $88 \%$, estando dentro do esperado para as condições experimentais.

$\mathrm{O}$ incremento do peso médio dos peixes nos três anos com a densidade de 15 peixes $/ \mathrm{m}^{2}$ foi de 8,88 ; 10,$23 ; 10,80$ e $11,88 \mathrm{~g}$, respectivamente, nos tratamentos I, II, III e IV. Para a densidade de 30 peixes $/ \mathrm{m}^{2}$, o resultado final foi 5,$49 ; 6,83 ; 8,06$ e $9,19 \mathrm{~g}$, respectivamente, nos tratamentos de I a IV (Tabela 2). Não ocorreu interação entre densidades e proteínas significativa na análise da variância pelo teste $\mathrm{F}(\mathrm{P}>0,05)$; por isso, os dois níveis de densidade e os quatro de proteína foram comparados de forma independente. A densidade 15 apresentou efeito superior a 30 pelo teste $\mathrm{F}$ da análise da variância. O efeito de proteínas foi significativo pelo teste $\mathrm{F}$ e seus graus de liberdade desdobrados em polinômios ortogonais. $\mathrm{Na}$ análise da regressão polinomial para ganho de peso em função dos quatro níveis de proteína na ração, a equação que melhor explica o comportamento é a linear: $\mathrm{Y}=4.23+0.27 \mathrm{X}$ (Figura 3).

Trabalhando com pacu (Piaractus mesopotamicus), Carneiro, Wagner e Dias (1992) concluem ser importante o aumento do teor de proteína bruta com o aumento da densidade. De acordo com Swingle (1968), Rosa et al.(1994), Coda et al.(1996), Graeff e Pruner (1996 ab) e Graeff e Pruner (1997 ab), a taxa de estocagem em cultivo é extremamente importante, pois se for muito baixa, resultará em peixes grandes e baixa produção; entretanto, se for muito elevada, resultará em alta produção com peixes de tamanho reduzido.

Ciênc. agrotec., Lavras. V.27, n.4, p.894-902, jul./ago., 2003 


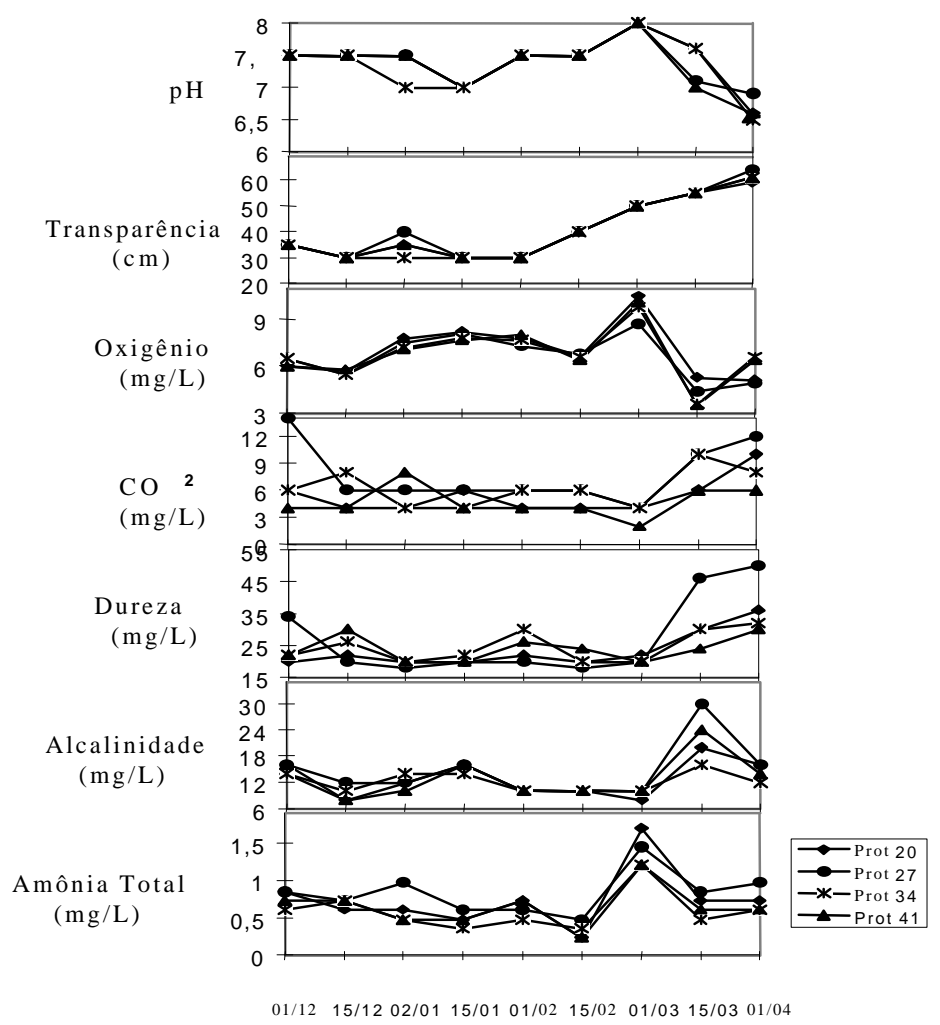

FIGURA 2 - pH, transparência $(\mathrm{cm})$, oxigênio dissolvido $(\mathrm{mg} / \mathrm{L})$, gás carbônico, amônia total e alcalinidade (mg/L) da água.

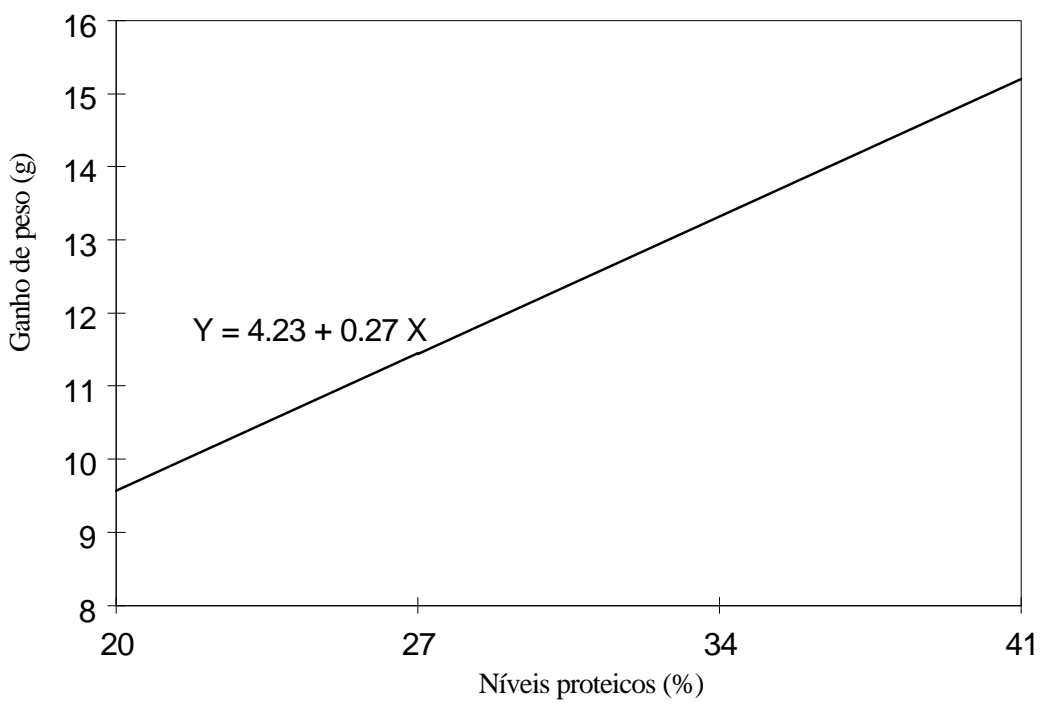

FIGURA 3 - Regressão polinomial para ganho de peso em função de 4 níveis de proteína bruta. 
A variável comprimento médio final dos peixes nos três anos apresentou, como resultado final para a densidade $15 / \mathrm{m}^{2}, 8,03 ; 8,24 ; 8,54$ e $8,98 \mathrm{~cm}$, respectivamente, nos tratamentos de I a IV e está indicado na Tabela 2. Para a densidade de 30 peixes, o resultado final foi 6,$76 ; 7,11 ; 7,57$ e $7 ; 83 \mathrm{~cm}$, respectivamente, nos tratamentos de I a IV (Tabela 2). Também não houve interação entre densidades e proteínas significativa; portanto, os fatores foram comparados independentemente. A densidade 15 foi superior a 30 pelo teste $\mathrm{F}$ da analise da variância. $\mathrm{O}$ efeito de proteínas foi significativo pelo teste $\mathrm{F}$ e também foi desdobrado em polinômios ortogonais. $\mathrm{Na}$ análise da regressão polinomial para comprimento médio em função dos quatro níveis de proteína na ração, a equação que melhor explica o comportamento também é a linear: $\mathrm{Y}=2.80+0.08 \mathrm{X}$ (Figura 4).

Na conversão alimentar média, o efeito de densidades nos três anos não foi significativo na analise da variância; portanto, as densidades não diferem (Tabela 3). Mas com a variação de 2,91 a $4,18 \mathrm{~g}$ de ração por grama de ganho de peso, a conversão alimentar neste trabalho é deficiente. Teimei e Deyoe, citados por Teimei et al. 1969, consideram que uma conversão acima de $2 \mathrm{Kg}$ de ração por quilograma de ganho de peso é insatisfatória. $\mathrm{Na}$ analise da regressão polinomial para conversão alimentar em função dos quatro níveis de proteína na ração, a equação que melhor explica o comportamento é linear:Y = $4.72-0.04 \mathrm{X}$ (Figura 5), o que Lovell (1979) confirma.

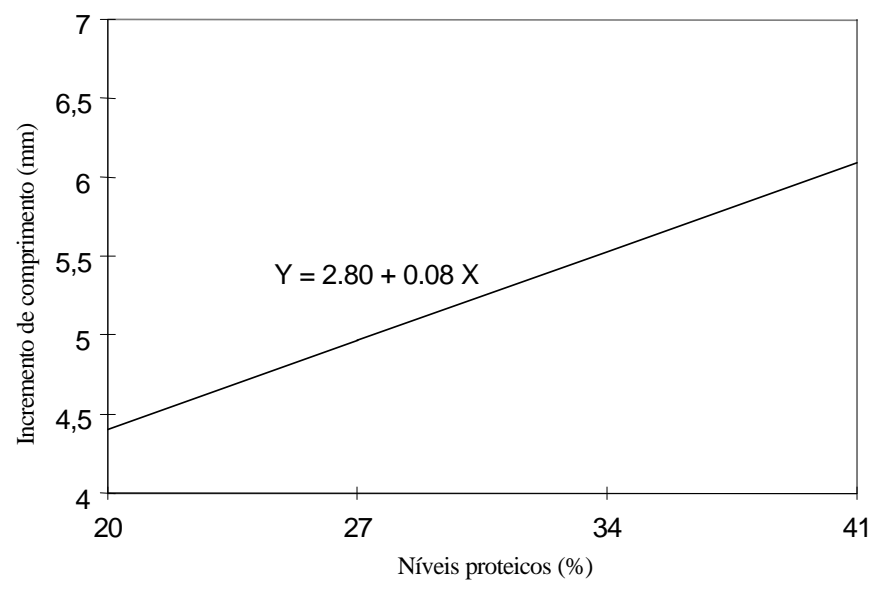

FIGURA 4 - Regressão polinomial para incremento do comprimento em função de 4 níveis de proteína bruta

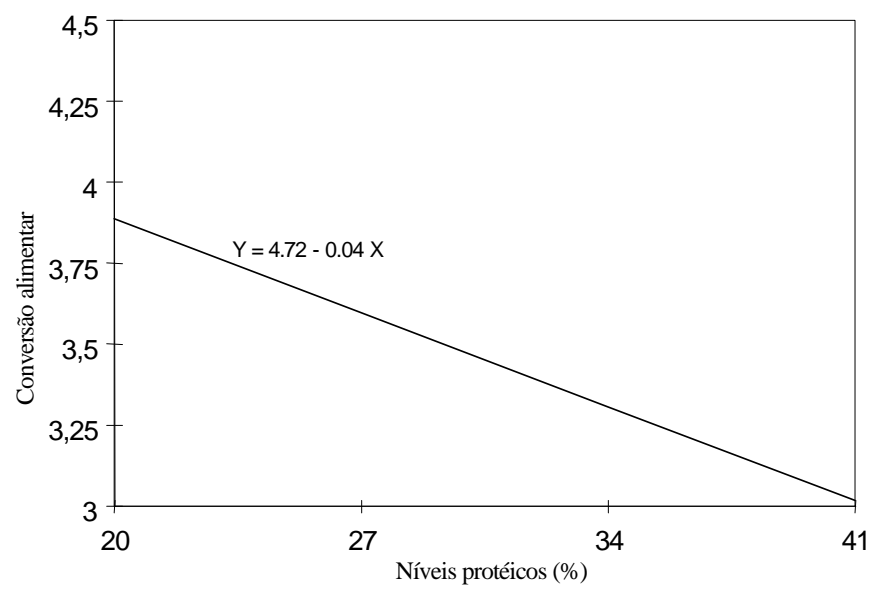

FIGURA 5 - Regressão polinomial para conversão alimentar em níveis de proteína bruta.

Ciênc. agrotec., Lavras. V.27, n.4, p.894-902, jul./ago., 2003 


\section{CONCLUSÕES}

a) A resposta aos níveis de proteína na ração foi linear, pois quanto maior o índice de proteína bruta, melhor foi o desempenho dos peixes.

b) Para as variáveis que indicam o crescimento individual dos peixes (peso e crescimento), a densidade de 15 alevinos $/ \mathrm{m}^{2}$ foi superior à de 30 alevinos $/ \mathrm{m}^{2}$.

\section{AGRADECIMENTO}

À Universidade do Contestado - UNC - Campi Caçador, pela colaboração e financiamento para o desenvolvimento deste trabalho.

\section{REFERÊNCIAS BIBLIOGRÁFICAS}

ARRIGNON, I.. Ecologia $Y$ piscicultura de águas dulces. Madri: Mundi-Prensa, 1979. 365p.

CAStagnOLli, N.. Piscicultura nos trópicos. São Paulo: Manole, 1986. 152p.

CAStagnOLli, N.. Piscicultura de água doce. Jaboticabal: Funep, 1992. 189p.

BOYD, C.E.. Manejo do solo e da qualidade da água em viveiro para aquicultura. Campinas: Associação Americana de Soja, 1997. 55p.

CARNEIRO, D.J., RANTIN, F.T., DIAS, T.C.R., MALHEIROS, E.B.. Níveis de proteína e energia bruta em dietas para crescimento de pacu, Piaractus mesopotamicus, em diferentes temperaturas. I Efeitos sobre o desempenho de produção. In: SIMPÓSIO BRASILEIRO DE AQUICULTURA, 6, Natal, 1990. Resumos... Natal: Simbraq, 1990. p. 59.

CARNEIRO, D.J., WAGNER, P.M., DIAS, T.C.R.. Efeito da densidade de estocagem e do nível de proteína bruta na dieta, no desempenho de produção de pacu (Piaractus mesopotamicus). In: SIMPÓSIO BRASILEIRO DE AQUICULTURA, 7, Peruibe, SP, 1992. Anais...Peruibe:Simbraq, 1992. p. 52-61.

CODA, S. FILHO, M.C., LEONHARDT, J.H., LUNDSTEDT, L.M.,DIAS, A.L.. Efeito da densidade de estocagem no cultivo intensivo de tilapia do nilo, Oreochromis niloticus. In: SIMPÓSIO BRASILEIRO DE AQUICULTURA, 9, Sete Lagoas, MG, 1996, Resumos... Sete Lagoas: Simbraq, 1996. p. 131.
COWEY, C.B.. Protein and amino acid requirements of fish. In: EIFAC /1978/SYMPOSIUM Hamburg, 1978, Proceedings... Hamburg: R/6. 1978. 20p.

DE LONG ,D.C., HALVER, J.E., MERTZ, E.T.. Nutrition of Salmonoid fishes: VI Protein requirement of chinook salmon at two water temperatures. J. Nutr. V.65, p.589-599, 1958.

GRAEFF, A.; PRUNER, E.N.. (a) Efeito de diferentes densidades de povoamento para o desenvolvimento do alevino II, Cyprinus carpio L. em Curitibanos/SC. In: SIMPÓSIO BRASILEIRO DE AQUICULTURA, 9, Sete Lagoas, MG, 1996, Resumos...Sete Lagoas: Simbraq, 1996. p.134

GRAEFF, A.; PRUNER, E.N.. (b) Efeito de diferentes densidades de povoamento para o desenvolvimento do alevino II, Cyprinus carpio L. em Rio das Antas/SC. In: SIMPÓSIO BRASILEIRO DE AQUICULTURA, 9, Sete Lagoas, MG, 1996, Resumos... Sete Lagoas: Simbraq, 1996. p.135.

GRAEFF, A.; PRUNER, E.N.. (a) Influência de diferentes densidades de povoamento no desenvolvimento do alevino I de Cyprinus carpio (L.), em $\mathrm{Cu}-$ ritibanos, S.C. B. Inst. Pesca, v.24(especial), p.267272, 1997.

GRAEFF, A.; PRUNER, E.N.. (b) Influência de diferentes densidades de povoamento no desenvolvimento do alevino I de Cyprinus carpio (L.), em Rio das Antas, S.C. B. Inst. Pesca, v.24(especial), p.263-278, 1997.

HUET, M.. Tratado de Piscicultura. Madrid: MundiPrensa, 1978. 705p.

KNIGHTS, B.. Agrovistic behaviour and growth in the European eel, Anquilla anquille $\mathrm{nL}$. in relation to warm-water aquaculture. J. fish biolog., v.31, p.265276, 1987.

LING, S.W.. Foods and feedinng of warm-water fishes in ponds in Asia and Far East. Bankok, Thailand, 1973. 201p.

LOVELL,R.T.. Alimento de peces y alimentacion. In: Curso de Entrenamiento de Acuicultura, Cartagena, 1979; International Center of Aquaculture, Auburn University, Alabama, 1979. 
LUKOWICZ, M.V. Intensive carp Cyprinus carpio L. rearing in a farm pond in southern Germany and its effects on water quality. .Aquaculture Engineers. v. 1, n. 2, p.121-137, 1982.

MAKINOUCHI, S.. Criação de carpa em água parada. Informe Agropecuário. Belo Horizonte, v.6, n.67, p. 30-47, 1980.

NATIONAL RESEARCH COUNCIL - Commitee on animal nutrition- Nutrient requirements of fish. Washington, DC:National Academy Press. 1993. $115 \mathrm{p}$.

NOSE, T.. Digestibility of carbohidrats in young raimbow trout. Bulletin of freshwater research laboratory, v.17, n.1, p.21-25, 1967.

PARKER, W.. Status and overwiew of fish culture systems and techniques in the United States. In: PROCEEDINGS 2nd INTERNATIONAL CONFERENCE OF AQUAFARMING, Verona, IT, 1984, Proceedings... Verona:Grimaldi \& Rosenthal Editors, 1984. p. 46-69.

PEREIRA FILHO, A.. Teor protéico ideal para alimentação de carpas (Cyprinus carpio L.) Cientifica , v.6, n.2, p.313-319, 1978.

PEZZATO, L.E., PACKER, I.U., PEZZATO, A.C., SILVEIRA, A.C.. Efeito de níveis de proteína sobre o crescimento da tilápia do nilo (Oreochromis niloticus), submetida à reversão sexual. In: SIMPÓSIO BRASILEIRO DE AQUICULTURA , 4, Cuiabá, MT, 1986 Anais.... Cuiabá: FUNEP, 1986. p.71-80.

ROSA, G.J.M., PEZZATO, L.E., SALARO, A.L., BARROS, M.M., DEL CARRATORE, C.R.. Desempenho produtivo de alevinos de carpa comum (Cyprinus carpio) em função de diferentes densidades de estocagem. In: SIMPÓSIO BRASILEIRO DE AQUICULTURA, 8, Piracicaba, SP, 1994, Resumos...Piracicaba: FEALQ, 1994. p. 24

SWINGLE, H.S.. Biological means of increasing productivity in ponds. In:FAO: WORD SYMP. ON WARMWATER POND FISH CULTURE. 1968, Anais...Italia:FAO, 1968

TAMASSIA,S.T.J., KREUZ, C.L.. Viabilidade econômica da recria de Carpas em Santa Catarina: Estudo de Casos. In: SIMPÓSIO BRASILEIRO DE AQUICULTURA, 5, Florianópolis, SC, 1988, Anais.... Florianópolis:ABRAq, 1990. p.603-607.

TEIMEI, O.W., DEYOE, C.W., LIPPER, R.. Influence of photoperiod on growth of fed channel cat-fish (Ictalurus punctatus) in early spring and late fall. Trans. Kansas Acad. Sci. v.72, p.519-522, 1969.

WOYNAROWICH, E.. Manual de piscicultura. Brasilia: MINTER/CODEVASF, 1985. 71p. 